\title{
The Effect of Additives on the Properties of Metakaolin and Fly Ash Based Geopolymers
}

\author{
Michał Łach ${ }^{1}$, Kinga Korniejenko ${ }^{1, *}$, Maria Hebdowska-Krupa ${ }^{1}$, Janusz Mikuła ${ }^{1}$ \\ ${ }^{1}$ Institute of Materials Engineering, Faculty of Mechanical Engineering, Cracow University of \\ Technology, Jana Pawła II 37, 31-864 Cracow, Poland
}

\begin{abstract}
The main motivation of research work is connected with environmental issues. The production of the most important building material of the 20th century - Portland cement technology is associated with significant environmental pollution. The process requires very high temperature and it is energy consuming. During the manufacturing also takes place emission of significant amounts of carbon dioxide and highly toxic nitrogen oxides into the atmosphere These factors show that new solution in this area is required. The most promising alternative is inorganic polymer (geopolymer) technology.

The main objective of the presented research work was to design a new composite for practical applications, especially in construction industry. The paper presents the results of research of geopolymer composites based on geopolymer binders made of metakaolin and fly ash with the addition of titanium oxide and aluminum-calcium cements (including mainly calcium monoglinate) in amount of 4 and $6 \%$ by weight. Research methods applied: tests for mechanical properties (compressive strength tests), scanning microscopy investigations (SEM) and X-Ray Diffraction (XRD).

The results show that the addition of aluminum-calcium cements (including calcium monoglinate) significantly increases the compressive strength of geopolymers. Geopolymers based on fly ash with the addition of $6 \%$ calcium-aluminum cement with a calcium monoglinate content above $69 \%$ are characterized by compressive strength above $50 \mathrm{MPa}$, while geopolymers from metakaolin with the same additive were characterized by compressive strength above $80 \mathrm{MPa}$.
\end{abstract}

\section{Introduction}

Geopolymers are a group of materials defining as inorganic aluminosilicate polymers with specific composition and properties. The name 'geopolymer' was first used by the French scientist Professor Joseph Davidovits in 1970. These materials have very high mechanical properties and excellent resistance to chemically aggressive environments, especially resistance to a variety of acids and salts [1,2]. They were initially developed as a fire resistant alternative to organic polymers. They have good fire resistance (up to $1000{ }^{\circ} \mathrm{C}$ ) and no

\footnotetext{
* Corresponding author: kinga.korniejenko@mech.pk.edu.pl
} 
emission of toxic fumes when heated $[3,4]$. Nowadays, the geopolymers are mainly applied in construction industry $[5,6]$.

The one of the limitations for wide use geopolymers is a common problem with efflorescence caused by excess sodium oxide remaining unreacted in materials [7]. It is usually indirect effect of the properties of the raw materials and manufacturing process. Raw materials for the production of geopolymers may be natural materials such as volcanic tuff or metakaolin as well as fly ash from a combined heat and power plant and blast furnace slag $[8,9]$. Geopolymers are created by reaction between alkaline solutions and solid aluminosilicates. The activation process requires high $\mathrm{pH}$. Research into the possibility of creating and developing geopolymer compositions for the best mechanical properties as well as without efflorescence effects are one of the most important area [10]. The limitation of efflorescence will allow to spread this material in industrial applications [11].

The appearance of efflorescence is caused by the elimination of sodium or potassium ions from the geopolymer structure. If products have contact with water or are in high moisture environment, the water leaches alkali ions through capillary action and moves them to the surface. After evaporation of water, these ions react with $\mathrm{CO}_{2}$ from the atmosphere and hydrated sodium or potassium carbonates are created $\left(\mathrm{Na}_{2} \mathrm{CO}_{3} \cdot \mathrm{nH}_{2} \mathrm{O}, \mathrm{NaHCO}_{3} \cdot \mathrm{nH}_{2} \mathrm{O}\right.$, $\mathrm{K}_{2} \mathrm{CO}_{3}$ ). This process will take a place in the materials when there are unreacted sodium or potassium oxides (cations) and the materials are characterized by high porosity [11,12]. The white efflorescence on the surface - it is sodium carbonate heptahydrate $\mathrm{Na}_{2} \mathrm{CO}_{3} \cdot 7 \mathrm{H}_{2} \mathrm{O}$ [11]. The identified carbonate crystallizes from inside the pores and 'grows' on the outside of the sample $[11,13]$. It can be a large problem, because it decreases not only aesthetic value for the final products, but also mechanical properties of the material $[10,11]$.

Exemplary research on additives for controlling efflorescence were made by Kani et al. [10]. They introduce aluminium rich mineral admixtures, such as: metakaolin (Zigma International, India), blast furnace slag (Isfahan Steel Complex, Iran), and three different calcium and aluminum cements Secar 71 (Kerneos, France), Secar 80 (Kerneos, France) and Koracast (Iran Refractory Products, Iran) into composition. These additives were introduced in the amounts of $2,4,6,8 \%$ by mass. In the case of the addition of slag and metakaolin, a very slight decrease in the tendency to efflorescence was observed, but in the case of calciumaluminum cements, much better positive effects in the reduction of efflorescence were observed.

According to the authors the reason for such effects may be the form of aluminium. In cements with a high aluminum content, aluminum is in the form of calcium aluminates, whereas in the slag and metakaolin it is in the form of aluminosilicates [10]. This important difference not only has an influence on results - different behaviours in the geopolymerization reactions, but also different compositions create the various reaction products $[10,14]$. The availability of calcium, not only its presence, is the most important point, because aluminium is more easily accessible from the $\mathrm{CaAl}_{2} \mathrm{O}_{4}$ phase dominating in Secar 71 than from $\mathrm{CaAl}_{4} \mathrm{O}_{7}$ and $\mathrm{Al}_{2} \mathrm{O}_{3}$ phases that are present in Secar 80. The most important effect is that geopolymerization reactions in the presence of admixtures cement with a high content of alumina lead to a more cross-linked aluminosilicate gel $[10,14]$.

However, the slag addition has a very slight influence on decreasing the tendency to efflorescence, but using it as an admixture has a positive influence on the mechanical properties of the composition. The use of slag as a reinforcing admixture and parameter modifier is mainly based on the introduction of calcium into the geopolymerization process. Calcium-containing gels help to create a more compact microstructure than those that consist only of fly ash. This is one of the main reasons for high strength achieved in slag containing geopolymers $[10,14]$. Other researches show that it is also necessary to investigate this problem long-term, because the $\mathrm{pH}$ and electrical conductivity values show different effects in two different curing conditions. The addition of slag increases the $\mathrm{pH}$ and electrical 
conductivity of the solution eluting for the hydrothermal heated samples, while for samples kept at room temperature, the addition of slag affects the lowering of $\mathrm{pH}$ and electrical conductivity. This means that the addition of calcium plays a different role depending on the temperature of annealing. In addition, it was found that the addition of slag, reduces the rate of alkali leaching to the solution, and thus reduces the rate of efflorescence, but only in the early phase, which suggests no impact on the potential for efflorescence in long-term $[8,9]$.

\section{Experimental}

\subsection{Materials}

The geopolymers were made from fly ash from the CHP plant in Skawina (Poland) and sand (ratio 1:1) with the various additions and from metakaolin form the Czech Republic and sand (ratio 1:1) with various additions.

The fly ashes were thoroughly investigated as a possible raw material for the production of the geopolymers. The chemical composition of the samples was determined by X-ray fluorescence (WD-XRF). They oxide composition is shown in Table 1.

Table1. Chemical composition of fly ash and metakaolin.

\begin{tabular}{|c|c|c|c|c|c|c|c|c|}
\hline & \multicolumn{7}{|c|}{ Oxide composition (wt.\%) } \\
\cline { 2 - 9 } & $\mathrm{SiO}_{2}$ & $\mathrm{TiO}_{2}$ & $\mathrm{Fe}_{2} \mathrm{O}_{3}$ & $\mathrm{Al}_{2} \mathrm{O}_{3}$ & $\mathrm{CaO}$ & $\mathrm{MgO}$ & $\mathrm{K}_{2} \mathrm{O}$ & $\mathrm{Na}_{2} \mathrm{O}$ \\
\hline Fly ash & 55.9 & 1.09 & 5.92 & 23.49 & 2.72 & 2.61 & 3.55 & 0.59 \\
\hline Metakaolin & 53.01 & 0.74 & 1.34 & 41.54 & 0.27 & 0.38 & 0.71 & 0.82 \\
\hline
\end{tabular}

Additives were introduced in the form of aluminum-calcium cements. They were the source of aluminum and calcium ions. The contents of the main ingredients in cements are shown in Table 2 . The composition of additives was given by the manufacturer.

Table 2. The contents of the main ingredients in the additives introduced into the geopolymer compositions.

\begin{tabular}{|c|c|c|c|c|c|c|}
\hline & $\mathbf{A l}_{2} \mathbf{O}_{3}$ & $\mathbf{C a O}$ & $\mathbf{S i O}_{2}$ & $\mathbf{F e}_{2} \mathbf{O}_{3}$ & $\begin{array}{c}\text { Main } \\
\text { phase }\end{array}$ & $\begin{array}{c}\text { Other } \\
\text { phases }\end{array}$ \\
\hline CCA 1 & $>41 \%$ & $>35.5 \%$ & $<4 \%$ & $<15 \%$ & $\mathrm{CA}$ & $\begin{array}{c}\mathrm{C}_{4} \mathrm{AF}, \mathrm{C}_{12} \mathrm{~A}_{7} \\
\mathrm{C}_{2} \mathrm{AS}\end{array}$ \\
\hline CCA 2 & $>69 \%$ & $>28 \%$ & $<0.5 \%$ & $<0.3 \%$ & $\mathrm{CA}_{2} \mathrm{CA}_{2}$, & $\mathrm{C}_{12} \mathrm{~A}_{7}, \alpha \mathrm{A}$ \\
\hline
\end{tabular}

The different variants of samples have been prepared for the tests (Table 3.). Geopolymer samples based on fly ash or metakaolin with various additions such as: $6 \%$ titanium dioxide and aluminum-calcium cements $-4 \%$ and $6 \%$ by mass.

Table 3. Compositions of samples prepared for testing.

\begin{tabular}{|c|c|c|c|c|c|}
\hline & \multicolumn{2}{|c|}{ Base } & \multicolumn{2}{|c|}{ Addition } \\
\hline & $\begin{array}{c}\text { Fly } \\
\text { ash }\end{array}$ & Metakaolin & CCA1 & CCA2 & $\begin{array}{c}\text { Titanium } \\
\text { dioxide }\end{array}$ \\
\hline FA.0 & + & - & - & - & - \\
\hline FA.1 & + & - & $4 \%$ & - & - \\
\hline FA.2 & + & - & $6 \%$ & - & - \\
\hline FA.3 & + & - & - & $4 \%$ & - \\
\hline FA.4 & + & - & - & $6 \%$ & - \\
\hline MET.0 & - & + & - & - & - \\
\hline
\end{tabular}




\begin{tabular}{|c|c|c|c|c|c|}
\hline MET.1 & - & + & $4 \%$ & - & - \\
\hline MET.2 & - & + & $6 \%$ & - & - \\
\hline MET.3 & - & + & - & $4 \%$ & - \\
\hline MET.4 & - & + & - & $6 \%$ & - \\
\hline TD & + & - & - & - & $6 \%$ \\
\hline
\end{tabular}

Geopolymers were prepared using a $12 \mathrm{M}$ aqueous $\mathrm{NaOH}$ solution together with aqueous sodium silicate (ratio 1:2).

\subsection{Geopolymer synthesis}

To produce geopolymers flakes of technical sodium hydroxide were used and an aqueous solution of sodium silicate (R-145) whose molar module was 2.5 and density was about 1.45 $\mathrm{g} / \mathrm{cm} 3$. The tap water was used instead of the distilled one. The alkaline solution was prepared by means of pouring the aqueous solution of sodium silicate over the solid sodium hydroxide. The water/binder ratio was 0.52 in case of metakaoline and 0.5 in case of fly ash. The solution was thoroughly mixed for 15 minutes in a low-speed mixer and allowed to equilibrate until a constant concentration and temperature. Next, the obtained paste was poured into cubic molds $150 \times 150 \times 150 \mathrm{~mm}$. The solidification was conducted on the vibratory table. Then the molds were heated for 24 hours at $75^{\circ} \mathrm{C}$ in the molds closed by foil, cooled to the ambient temperature, taken out of the molds and stored for 28 days and 90 days. The samples were stored in controlled conditions: in the temperature $20^{\circ} \mathrm{C}$ and humidity $60 \%$.

\subsection{Examination methods}

The morphology of the samples was examined by means of the scanning microscope JEOL JSM 820. The ashes had been properly prepared before i.e. dried to the constant mass, put on the coal base to carry the electric charge of the sample away, and covered with thin layer of gold with the JEOL JEE-4X vacuum evaporator.

Compressive strength tests according to EN 12390-3, using Matest $3000 \mathrm{kN}$, were conducted on cubic samples $150 \times 150 \times 150 \mathrm{~mm}$ conditioned at room temperature for 28 or 90 days. Five repetition were carried out for each type of sample.

The phase composition was determined using powder X-ray diffraction Debye-ScherrerHull method. Diffractograms of samples W1A and W2A were recorded with the use of a Rigaku SmartLab X-ray diffractometer using the following parameters: $\mathrm{CuK} \alpha$ radiation, a graphite reflection monochromator, tube voltage $45 \mathrm{kV}$, tube current 200, step scan mode: step size $=0.05^{\circ} 2 \theta$, count time per $1 \mathrm{step}=1 \mathrm{~s}$. The values of interplanar distances obtained from diffractograms were used for the identification of phases present in the samples based on data contained in the ICDD (International Centre for Diffraction Data 2014) Catalogue and XRAYAN software.

\section{Results and discussion}

The results from the compressive strength test are shown in Table 4. The increasing of the compressive strength for the samples with additives is significant. The reference samples based on fly ash, without additives has about $37.8 \mathrm{MPa}$. The best results were achieved for geopolymer with a $6 \%$ addition of CCA2 - 53.5 MPa. The addition of CCA1 have also positive influence on mechanical properties. However, this addition requires the optimization in reference to amount, the better results have been obtained for $6 \%$ addition by mass $-50.0 \mathrm{MPa}$.

In the case of metakaolin-based geopolymers, a significant increase in compressive 
strength is observed up to the value of $89.2 \mathrm{MPa}$ for the composition containing $6 \% \mathrm{CCA} 1$.

Table 4. The results of compressive strength tests.

\begin{tabular}{|c|c|}
\hline & Compressive strength [MPa] \\
\hline FA.0 & 37.8 \\
\hline FA.1 & 50.0 \\
\hline FA.2 & 44.0 \\
\hline FA.3 & 50.0 \\
\hline FA.4 & 53.5 \\
\hline MET.0 & 66.0 \\
\hline MET.1 & 73.8 \\
\hline MET.2 & 89.2 \\
\hline MET.3 & 75.9 \\
\hline MET.4 & 77.6 \\
\hline TD & 45.0 \\
\hline
\end{tabular}

The XRD studies for samples have been made. Chosen results are presented in Fig. 1 and 2. XRD analysis allowed the identification of the following minerals in the studied materials:

- $\quad$ in sample FA.4: feldspars, illite, leucite, mullite, plagioclase, quarz;

- $\quad$ in sample MET.4: feldspars, illite, leucite, plagioclase and quartz.

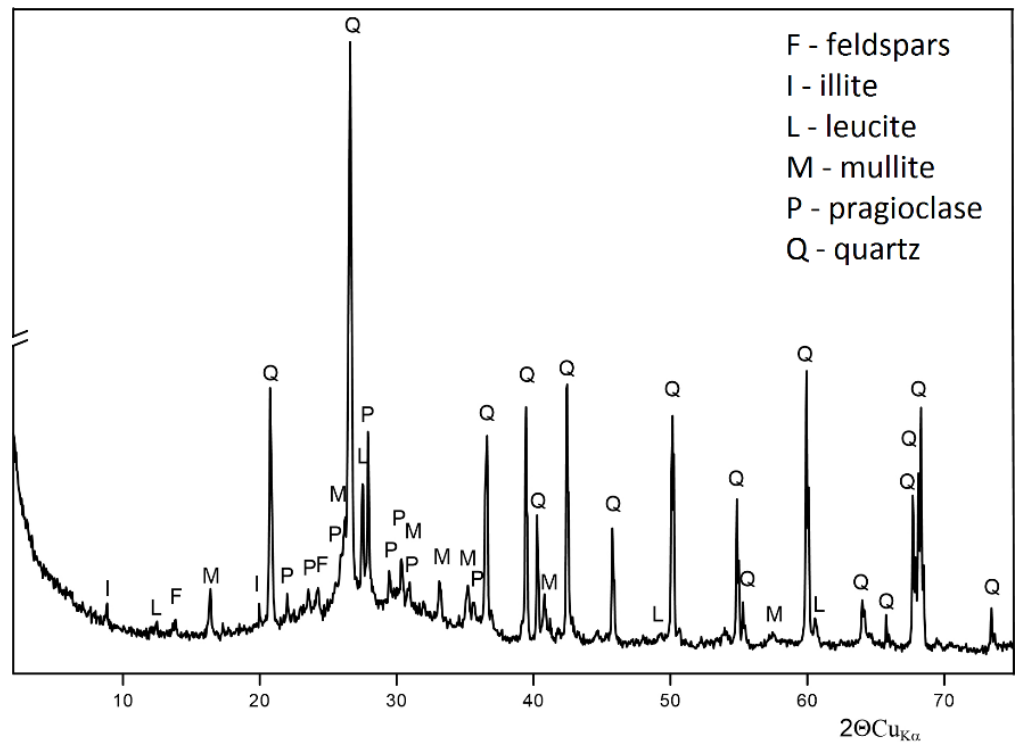

Fig. 1. XRD pattern of the fly ash based geopolymer (sample FA.4). 


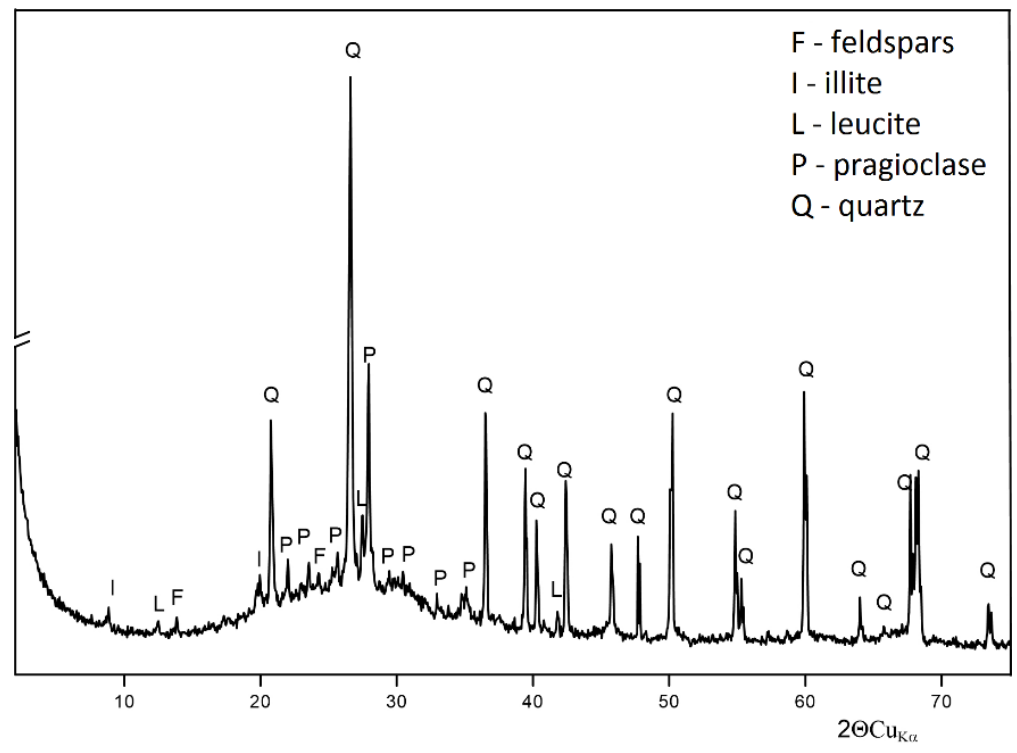

Fig. 2. XRD pattern of the metakaolin based geopolymer (sample MET.4).

The SEM observations were made for each composition. The results are presented in Fig. $3,4,5$ and 6 . A different character of the morphology for various samples is visible. Pores and cracks are noticeable.
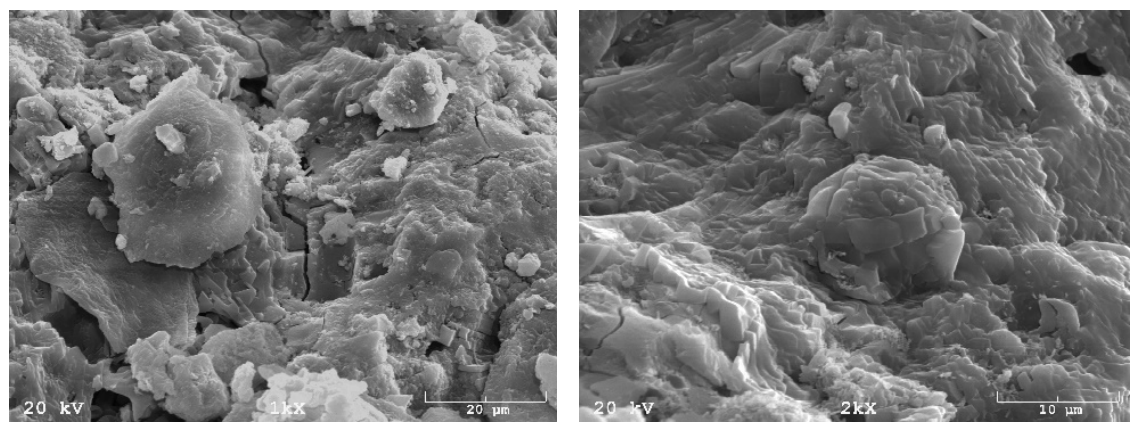

Fig. 3. SEM images of fly ash based geopolymer with $6 \%$ CCA 1.
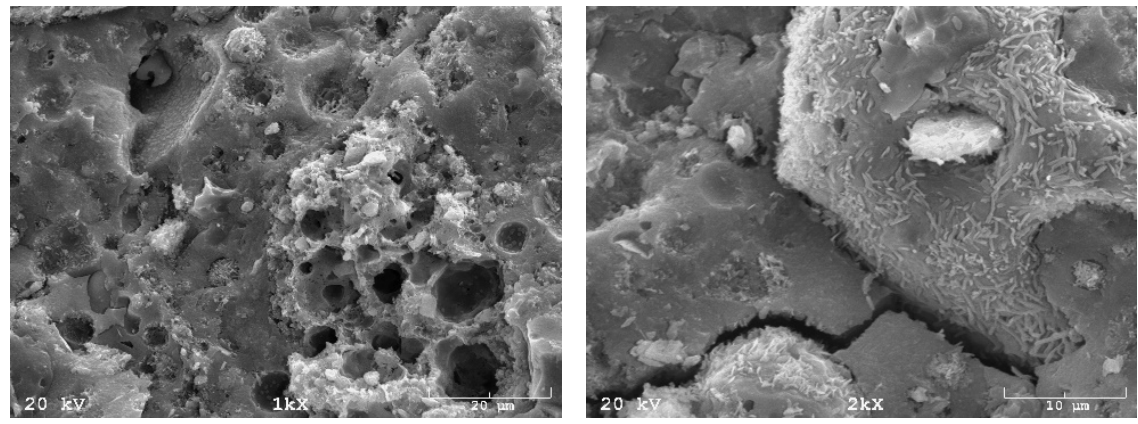

Fig. 4. SEM images of fly ash based geopolymer with 6\% CCA 2. 

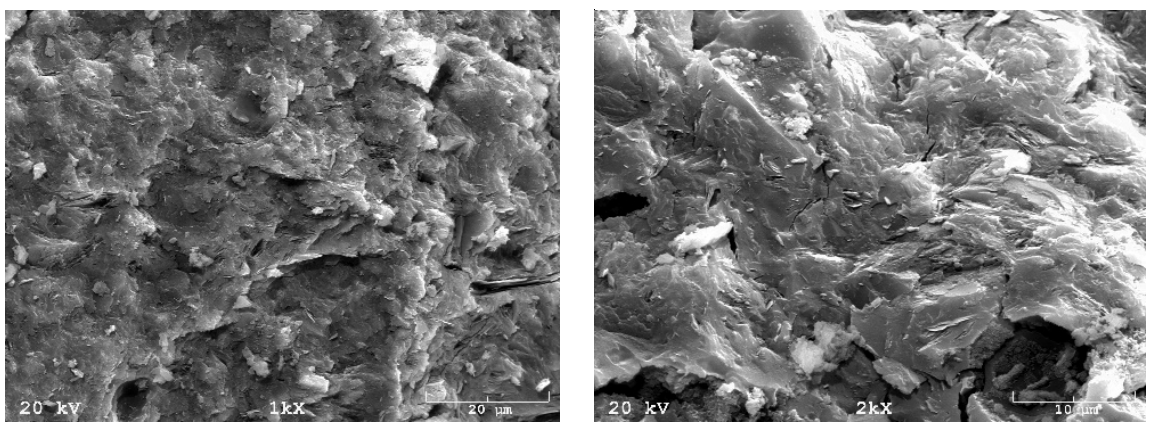

Fig. 5. SEM images of metakaolin based geopolymer with $6 \%$ CCA 1.
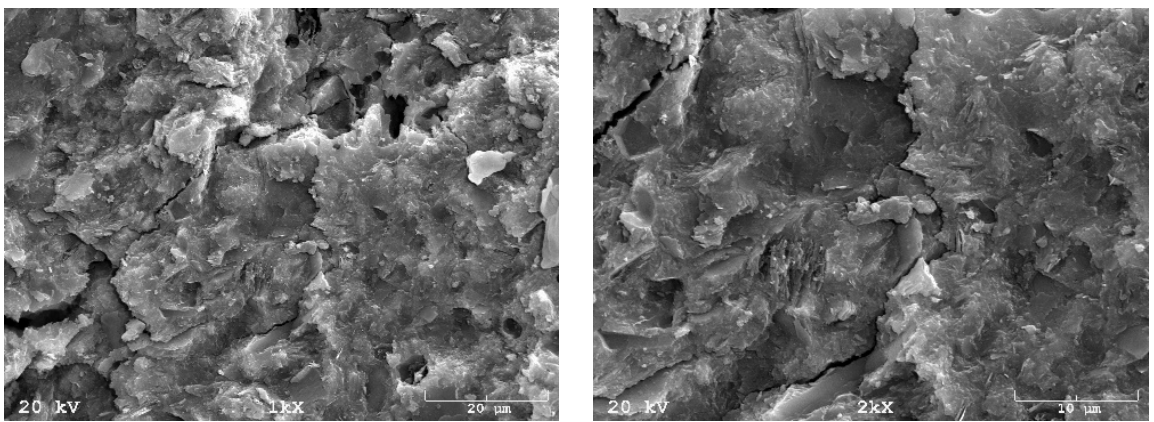

Fig. 6. SEM images of metakaolin based geopolymer with 6\% CCA 2.

The conducted research are confirmed by literature reports about the increase of compressive strength by additives such as aluminum-calcium cements and titanium oxide on geopolymers. The admixtures of aluminum-calcium cements increase compressive strength values for both fly ash based and metakaolin based geopolymers. The addition of $6 \%$ calcium-aluminum cement with an calcium monoglinate content above $69 \%$ results in a $40 \%$ increase in compressive strength in geopolymers based on fly ash. In the case of metakaolinbased geopolymers, the increase in compressive strength was also observed - about 35\% (in case of $6 \%$ admixture containing: above $41 \%$ of $\mathrm{Al}_{2} \mathrm{O}_{3}$ and above $35 \% \mathrm{CaO}$ ).

\section{Conclusions}

The main objective of the presented research work was to design a new composite for practical applications. The results shows that the addition of calcium monoglinate significantly increases the compressive strength of geopolymers. Geopolymers based on fly ash with the addition of $6 \%$ calcium-aluminum cement with a calcium monoglinate content above $69 \%$ are characterized by compressive strength above $50 \mathrm{MPa}$, while geopolymers from metakaolin with the same additive were characterized by compressive strength above $80 \mathrm{MPa}$.

The available literature also mention the favourable effect of aluminum-calcium cements on the process of limiting efflorescence on geopolymers. However, this phenomena is not fully described and not completely explained. It requires further detailed research. The authors of this article are in the process of conducting such research and determining the influence of calcium-aluminum additives on the process of limiting efflorescence.

This work was supported by the ERANet-LAC 2nd Joint Call (http://www .eranet-lac.eu) and funded by National Centre for Research and Development, Poland, under grant: "Development of eco-friendly composite materials based on geopolymer matrix and reinforced with waste fibers". 


\section{References}

1. J. Davidovits, Geopolymer chemistry and application (Geopolymer Institute, SaintQuentin, France, 2015)

2. A. Palomo, M.T. Blanco-Varela, M.L. Granizo, F. Puertas, T. Vazquez, M.W. Grutzeck, Cem. Concr. Res. 29, 7 (1999)

3. J. Davidovits J., J. Therm. Anal. 37, 8 (1991)

4. R.E. Lyon, P.N. Balaguru, A. Foden, U. Sorathia, J. Davidovits, M. Davidovits, Fire Mater. 21, 2 (1997)

5. L. Provis, J.S.J. van Deventer, Geopolymers: structure, processing, properties and industrial applications (Elsevier, New York, 2009)

6. M. Łach, K. Korniejenko, J. Mikuła, Procedia Eng. 151 (2016)

7. G.F. Huseien, J. Mirza, M. Ismail, S.K. Ghoshal, A.A. Hussein, Renewable and Sustainable Energy Reviews 80 (2017)

8. J. Davidovits, Market Trends and Potential Breakthroughs; Geopolymer 2002 Conference (2012)

9. Xu H., J. van Deventer, Int. J. Miner. Process. 59, 3 (2000)

10. E.K. Kani, A. Allahverdi, J.L. Provis, Cem. Concr. Compos. 34 (2012)

11. Z. Zhang, H. Wang, J.L. Provis, A. Reid, Efflorescence: A Critical Challenge for Geopolymer Applications?, (University of Southern Queensland, Toowoomba, Australia, 2013)

12. J. Mikuła, M. Łach, Geopolimery - nowa przyjazna środowisku alternatywa dla betonów na bazie cementu portlandzkiego. Przykłady zdrożenia $i$ wyniki badań [in:] Rozwiązania proekologiczne w zakresie produkcji, J Mikuła rd. (Politechnika Krakowska, 2014)

13. A. Palomo, M.W. Grutzeck, Cem. Concr. Res. 29, 8 (1999)

14. N. Sedira, J. Castro-Gomes, G. Kastiukas, X. Zhau, A. Vargas, Mining Sci. 24 (2017) 